Review article

\title{
Cancer incidence and mortality in Poland
}

\author{
Urszula Religioni \\ Warsaw School of Economics, Madalińskiego 6/8, 02-513, Warsaw, Poland
}

\section{A R T I C L E I N F O}

\section{Keywords:}

Cancer

Poland

Epidemiology

Incidence

Mortality

\begin{abstract}
A B S T R A C T
Objective: This article presents the epidemiology of cancer in Poland.

Methods: Data from the National Cancer Registry were used.

Results: It was found that the highest number of cancer cases among women concerns breast (22.8\%), lung (9.5\%) and colorectal cancer (9.0\%), and among men: prostate cancer (19.3\%), lung cancer (17.5\%) and colorectal cancer $(11.5 \%)$. The main cause of cancer deaths for both women and men is lung cancer.

Conclusion: Information on the burden of population cancer is the basis for determining health priorities, including methods that will have the greatest impact on the patient quality of life.
\end{abstract}

\section{Introduction}

Cancer is the first cause of death worldwide in developed countries and the second cause of death in developing countries. ${ }^{1,2}$ Every year, cancer is diagnosed in 18.1 million people in the world and kills 9.5 million people. ${ }^{3}$ The most commonly diagnosed cancers are lung (11.6\%), breast $(11.6 \%)$, prostate $(7.1 \%)$ and colorectal $(6.1 \%)$. The most common causes of cancer death were lung cancer $(18.4 \%$ of the total cancer deaths), colorectal cancer (9.2\%), stomach cancer (8.2\%), and liver cancer $(8.2 \%){ }^{4}$

In 2012 (latest year available), an estimated 2.7 million new cases of cancer were diagnosed in European Union (EU) member states, around 1.5 million occurring in men and 1.2 million in women. At the same time, 1.3 million of cancer deaths were registered $(29.2 \%$ of all male deaths and $22.5 \%$ of all female deaths). ${ }^{5,6}$

In Europe, the most common cancer site was breast cancer $(12.4 \%$ of all new cancer cases), followed by colorectal cancer (11.8\%), lung cancer $(11.1 \%)$ and prostate cancer $(10.6 \%))^{7}$ These four cancers account for half of all cancer cases in Europe. ${ }^{8}$ The highest incidence rates have been recorded in the northern and western Europe. The most common causes of cancer death were lung cancer (20.5\%), colorectal cancer $(8.1 \%$ deaths), and breast cancer $(7.1 \%$ deaths). The risk of cancer before the age of 75 is estimated at $27 \%$ (31\% for men and $24 \%$ for women) and the risk of death from cancer before the age of 75 is estimated at $12 \%$ ( $14 \%$ for men and $9 \%$ for women). ${ }^{6,7,9,10}$

After cardiovascular diseases, cancer is the second cause of deaths in Poland (24.1\% deaths in women and $27.3 \%$ in men in 2016). In the last 30 years, the number of new cancer cases in Poland has doubled. The total number of cancer cases in Poland in 1980 was 64,820 (crude rate: $182.2 / 100,000$ ) whereas in 2016 it amounted to 164,140 (427.1/
100,000). In 1980 the crude cancer incidence rate among women was $168.5 / 100,000$ whereas in 2016 it reached $411.5 / 100,000$. The same value for men in 1980 was 196.6/100,000 and in 2016 it reached 443.9. The growth rate for cancer cases in recent years has been similar for men and women. Nevertheless, considering standardized cancer incidence rates, these values are lower in Poland than in the EU. ${ }^{11,12}$

The number of cancer deaths in Poland is increasing. In the last 50 years it has risen by 2.5 times. Available data show that the number of cancer deaths in 1965 and in 2016 was 38,956 (crude death rate: 123.7) and 99,965 (crude death rate: 260.1 ), respectively. Crude death rate in women has increased from 119.4 in 1965 to 225.4 in 2016. The same rates for men were 128.2 in 1965 and 297.2 in 2016. Cancer constitutes a much greater risk for men than women. In 2016, the standardized death rate for men was by $85.7 \%$ higher than the death rate for women. ${ }^{13}$ The most common types of cancer causing death among Poles (men and women) are lung cancer, colorectal cancer and stomach cancer.

Cancer mortality in Poland is higher than in the EU. Although cancer survival rates in Poland show that effectiveness of cancer treatment in Poland is increasing, the overall 5-year survival rate is one of the lowest in Europe. ${ }^{11,14}$

\section{Cancer incidence among women}

In 2016 cancer incidence in women in Poland was 81,620. Most cases were diagnosed in women $45-64$ years of age (about $50 \%$ of cases). Regarding the age group 20-44 years, cancer incidence in Poland is much higher in women than men $(101 / 100,000$ women in 2016 vs $52 / 100,000$ men). For many years, a growing trend of higher cancer incidence in the group of young women has been observed. The

E-mail address: urszula.religioni@gmail.com. 
Table 1

Incidence and deaths from the most common cancer among women and men in Poland, 2016.

\begin{tabular}{|c|c|c|c|c|}
\hline \multicolumn{5}{|l|}{ New cancer incidence } \\
\hline \multicolumn{5}{|l|}{ Women } \\
\hline Type of cancer & ICD-10 & Number of incidence (\%) & Crude rate & Standarized rate per 100,000 \\
\hline Breast cancer & C50 & $18,615(22.8)$ & 93.8 & 54.1 \\
\hline Lung cancer & C34 & $7,730(9.5)$ & 39.0 & 19.1 \\
\hline Colorectal cancer (colon + rectum) & C18-C19 & $7,358(9.0)$ & 37.1 & 16.4 \\
\hline Endometrial cancer & C54 & $6,266(7.7)$ & 31.6 & 16.4 \\
\hline Ovarian cancer & C56 & $3,717(4.6)$ & 18.7 & 10.9 \\
\hline \multicolumn{5}{|l|}{ Men } \\
\hline Type of cancer & ICD-10 & Number of incidence (\%) & Crude rate & Standarized rate per 100,000 \\
\hline Prostate cancer & C61 & $15,961(19.3)$ & 85.9 & 48.3 \\
\hline Lung cancer & C34 & $14,466(17.5)$ & 77.8 & 44.4 \\
\hline Colorectal cancer (colon + rectum) & $\mathrm{C} 18-\mathrm{C} 19$ & $9,528(11.5)$ & 51.3 & 29.0 \\
\hline Urinary bladder cancer & C67 & $5,413(6.6)$ & 29.1 & 16.0 \\
\hline Gastric cancer & C16 & $3,479(4.2)$ & 18.7 & 10.7 \\
\hline \multicolumn{5}{|l|}{ Deaths from cancer } \\
\hline \multicolumn{5}{|l|}{ Women } \\
\hline Type of cancer & ICD-10 & Number of incidence (\%) & Crude rate & Standarized rate per 100,000 \\
\hline Lung cancer & C34 & $7,635(17.1)$ & 38.5 & 17.7 \\
\hline Breast cancer & C50 & $6,493(15.5)$ & 32.7 & 14.9 \\
\hline Colorectal cancer (colon + rectum) & C18-C19 & $4,936(11.0)$ & 24.5 & 9.4 \\
\hline Ovarian cancer & C56 & $2,639(5.9)$ & 13.3 & 6.4 \\
\hline Pancreatic cancer & $\mathrm{C} 25$ & $2,512(5.6)$ & 12.7 & 5.1 \\
\hline \multicolumn{5}{|l|}{ Men } \\
\hline Type of cancer & ICD-10 & Number of incidence (\%) & Crude rate & Standarized rate per 100,000 \\
\hline Lung cancer & C34 & $16,177(29.3)$ & 87.0 & 48.5 \\
\hline Colorectal cancer (colon + rectum) & C18-C19 & $6,321(11.5)$ & 34.0 & 18.2 \\
\hline Prostate cancer & C61 & $5,220(9.4)$ & 28.1 & 13.8 \\
\hline Gastric cancer & C16 & $3,353(6.1)$ & 18.0 & 10.0 \\
\hline Urinary bladder cancer & $\mathrm{C} 67$ & $2,967(5.4)$ & 16.0 & 8.2 \\
\hline
\end{tabular}

standardized cancer incidence rate among women in Poland was 225.4 in 2016 (and 219.1 in 2013), which was much lower than the average of EU countries (327.9). ${ }^{11}$ In the group of women, the overall rate of 1year survival with cancer is $76 \%$, whereas the 5 -year survival rate is $56 \% .^{12}$

The most common types of cancer in women in Poland are breast cancer (over $22.8 \%$ of all cases), lung cancer (9.5\%), colorectal cancer (9\%, including colon cancer $6.3 \%$ and rectum cancer $2.7 \%$ ), endometrial cancer $(7.7 \%)$ and ovarian cancer (4.6\%) (Table 1). These diseases are followed by thyroid cancer, cervical cancer, kidney cancer, melanoma and stomach cancer ${ }^{12}$ (Figs. 1 and 2).

Breast cancer is the most common cancer in women in Poland. The number of breast cancer cases in 1980 was 5,144 (crude rate: 28.2/ 100,000), whereas in 2016 this number was over three times higher and amounted to 18,615 (crude rate: 93.8 ). ${ }^{12}$ The number of breast cancer cases in Poland is much lower than in the EU countries (in 2013 the standardized incidence rate for Poland is 51.8 and for the EU 106.6). ${ }^{15}$ In the last 30 years the incidence in adult women in premenopausal age (20-49 years) has increased almost twice. The 1-year and 5-year

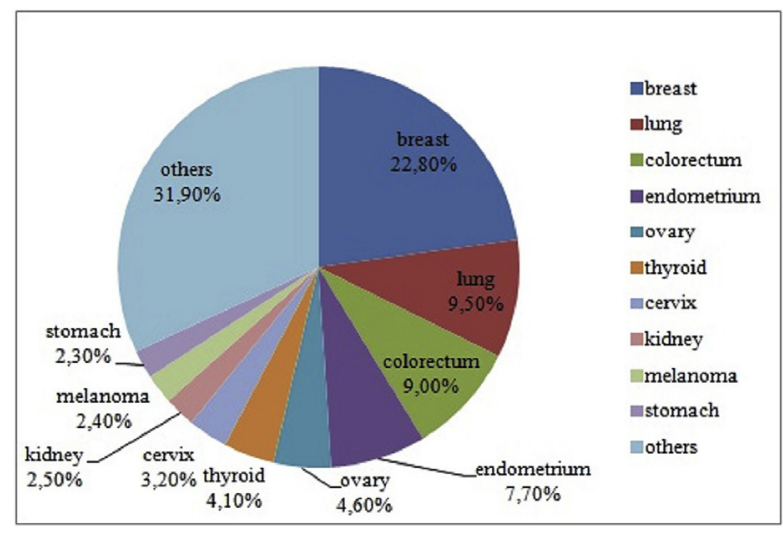

Fig. 1. Cancer incidence among women, 2016.

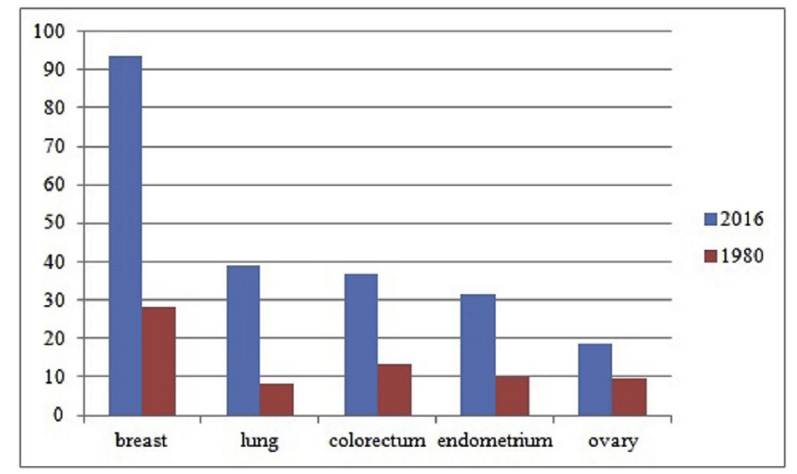

Fig. 2. Cancer incidence among women in 2016 and 1980 (crude rate).

survival rates are estimated at $94.4 \%$ and $78.5 \%$.

The second most common type of cancer in women (similar to men) is lung cancer. The number of lung cancer cases in women in 2016 was 7,730 (crude rate: 39.0 ), and in 1980 it amounted to 1,503 (crude rate: 8.2). Over these years, the increase in the incidence of lung cancer in women was constant. ${ }^{16}$ Incidence rate for lung cancer in women in Poland is lower than in the EU $(18.3 / 100,000$ and $26.1 / 100,000$ in 2013 , respectively). ${ }^{17}$ The risk of lung cancer increases with age. The average 1-year and 5-year survival rates for lung cancer in women are $47.2 \%$ and $18.5 \%$, respectively, and they are higher than in men. ${ }^{12}$

Colorectal cancer is the third most common cancer in women (in men it also ranks third). In the last 30 years the number of colorectal cancer cases among women has increased three times. ${ }^{18}$ In 1980, the number of colorectal cancer cases among women was 2,432 (crude rate: 13.3), and in 2016 it amounted to 7,358 (crude rate: 37.1 ). The incidence of colorectal cancer among women in Poland is lower than the average for women in the EU countries (18.8/100,000 and 36.1/ 100,000 in 2013, respectively). Colorectal cancer occurs most frequently in women aged over 60 (about $75 \%$ of cases). ${ }^{19}$ The 1 -year and 5 -year survival rates for colon cancer in women are $76.6 \%$ and $52.4 \%$, 
respectively and for rectum cancer the rates was 78.7\% (1-year survival rate) and $48.4 \%$ (5-year survival rate). ${ }^{12}$

Endometrial cancer accounts for $7.7 \%$ of cancer cases in women in Poland, ranking the fourth most common type of cancer. In the last 30 years, a 2.5-fold increase in the incidence of this type of cancer has been observed in Poland. In 1980, the number of reported cases was 1,827 $(10 / 100,000)$, whereas in 2016 it amounted to 6,266 (crude rate: 31.6). For the last few decades, the incidence of endometrial cancer in young women has remained stable. The 1-year and 5-year survival rates for this group of patients in Poland are estimated at $91.8 \%$ and $77.1 \%$, respectively. ${ }^{20}$

Ovarian cancer is the fifth most common cancer in women in Poland. In the last 30 years, the number of new cases has increased two times. In 1980, the number of cases was 1,728 (crude rate: 9.5), and in 2016 it amounted to 3,717 (18.7). The incidence of ovarian cancer in Poland is about $15 \%$ higher than in the EU countries. Ovarian cancer accounts for approximately $4 \%$ of cancer cases diagnosed in children (0-19 years) and over $6 \%$ of cases diagnosed in young adults (20-44 years). The risk of ovarian cancer increases with age, with the biggest number of cases diagnosed in women aged over 50. The incidence of ovarian cancer in Poland increased particularly quickly until mid 1990s, after which it became stable. 1-year and 5-year survival rates for women with ovarian cancer are $72.2 \%$ and $43.9 \%$, respectively. ${ }^{12,21}$

\section{Cancer incidence among men}

The number of new cancer cases among men in 2016 in Poland was 82,520 . As in women, the vast majority of cancer cases (about 70\%) occurs in men over 60 years of age and the risk of cancer increases with age. The standardized rate of cancer (per 100,000) among men in Poland in 2016 was 260.9, which was lower than in EU countries. The overall survival rate for men with a one-year survival is $65 \%$, and the 5 year survival rate is $41 \% .{ }^{11,12}$

The most common cancers in men in Poland are prostate cancer (19.3\% of all cancers), lung cancer (17.5\%), colorectal cancer (11.5\%), bladder cancer (6.6\%) and stomach cancer (4.2\%) (Table 1), followed by kidney cancer, laryngeal cancer, pancreatic cancer, melanoma and brain cancer (Figs. 3 and 4).

Prostate cancer is the most common cancer among men in Poland. ${ }^{22}$ Over the past three decades, the incidence of prostate cancer in Poland has increased fivefold, with the highest growth rate since the 1990s. Despite this fact, the incidence of prostate cancer in Poland is lower by half than in other European countries (the standardized ratio for Poland in 2013 was 39.2, and for the EU - 105.5). ${ }^{23}$ In 1980, the number of cases was 1,731 (crude rate: 10.0/100,000), and in 2016-15,961 (85.9). The majority of prostate cancer cases occur among men over 60 years of age. The 1-year survival rate for men with prostate cancer is $92 \%$, and 5-year survival rate $-75.8 \%$.

Lung cancer ranks second in terms of morbidity in men, and the risk of lung cancer is three times higher in men than in women. The number

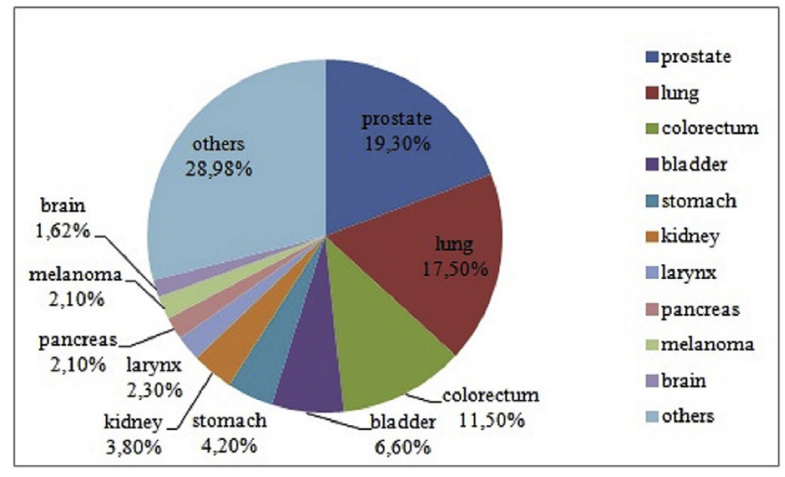

Fig. 3. Cancer incidence among men, 2016.

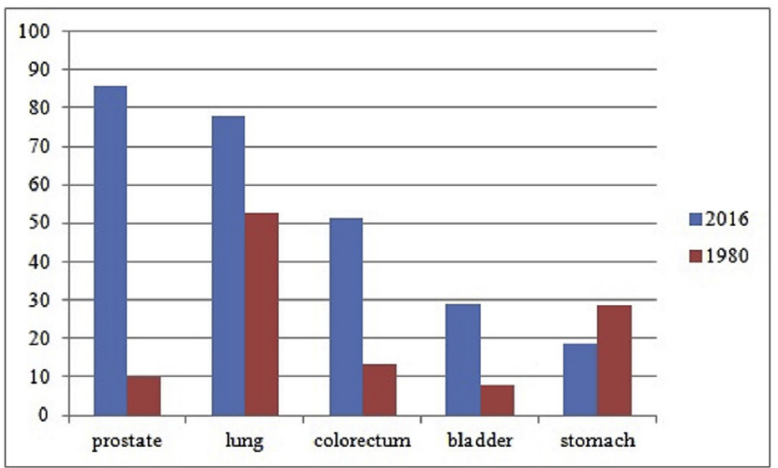

Fig. 4. Cancer incidence among men in 2016 and 1980 (crude rate).

of new lung cancer cases in 2016 among men in Poland amounted to 14,466 (crude rate: 77.8/100,000), and in 1980 it was 9,041 (52.5). The incidence of lung cancer in men in Poland increased markedly until the 1990s, followed by a systematic fall in the number of cases. Currently, the incidence of lung cancer among men in Poland is lower than the average incidence for EU countries (standardized ratio per 100,000: 48.1 vs. 66.3 in 2013). The vast majority of lung cancer cases in men occur over 50 years of age, and the accumulation of cases is observed among men over $70 .{ }^{17,24}$ The survival rate of men with lung cancer is lower than in the group of women and for 1-year it is $40.6 \%$, and for 5-year - $12.6 \%$.

Colorectal cancer is the third most common cause of cancer in men. The number of colorectal cancer cases in men in 1980 was 2,288 (crude rate: $13.2 / 100,000$ ), followed by a 5 -fold increase in cases, which amounted to 9,528 cases in $2016(51.3 / 100,000)$. The increase in men's rates has been particularly rapid since the beginning of the 21st century, ${ }^{18}$ but now the trend has stabilized. The incidence of colorectal cancer among men in Poland is lower than in other EU countries (the same relationship affected women). The standardized incidence rate per 100,000 for men in Poland in 2013 was 31.1, and in the EU - 59.0. ${ }^{19}$ The risk of colorectal cancer increases with age and in men it is about two times higher than in women. The survival rate with colorectal cancer in men is similar to women and amounted for $76.3 \%$ (1-year) and $48.3 \%$ (5-year) for colon cancer, and in the case of rectal cancer, these rates are $78 \%$ and $45 \%$, respectively.

Bladder cancer is the fourth most common cancer in men. Bladder cancer account for about $7 \%$ of new cancer cases in men and $2 \%$ of cases in women. The number of new bladder cancer cases in men in 2016 amounted to 5,413 (crude rate: 29.1/100,000), and in 1980 it was 1,402 (8.1), which reflects the rapidly growing trend of bladder cancer incidence. However, it is estimated that the incidence of bladder cancer in Poland is lower than the average of EU countries. ${ }^{25}$ The incidence of bladder cancer among men is about four times higher than in women. The 1-year survival rate in men with bladder cancer is $79.7 \%$, and 5year - $54.9 \%$.

Stomach cancer is the fifth most common cancer in men, which is also in the top ten of the most common cancers among women. Until the 1970s, stomach cancer in Poland was the most common cancer among men. The incidence of stomach cancer is systematically decreasing (within 30 years it has decreased by about 2 times). ${ }^{24}$ Despite this, the incidence of stomach cancer among men in Poland is higher than in EU countries. In 1980, among men in Poland, there were 4,847 new stomach cancer cases (crude rate: 28.8/100,000), and in 2016-3,479 (18.7). The risk of stomach cancer increases with age and in men is about three times higher than in women. The 1-year survival rate with stomach cancer in men in Poland is $36.8 \%$, and 5-year $19 \% .^{12,26}$ 


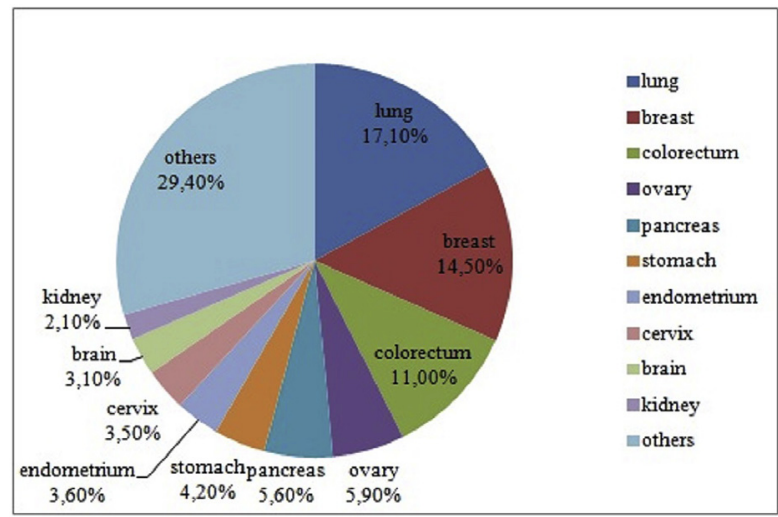

Fig. 5. Cancer mortality among women, 2016.

\section{Cancer mortality among women}

Almost 4,500 women a year die in Poland due to cancer (year 2016: 44,720 deaths), and the standardized death rate has been stable for years. Cancer mortality in women in Poland is lower than in the EU (standardized rates in 2013 were 97.0 and 128.4, respectively). ${ }^{11}$ The most common cause of death in women with cancer is lung cancer (17.1\% of all cancer deaths). Other types of cancer that cause the biggest number of deaths among women in Poland are breast cancer (14.5\% of deaths), colorectal cancer (11.0\%), ovarian cancer $(5.9 \%)$, and pancreatic cancer (5.6\%) (Table 1). These diseases are followed by stomach cancer, endometrial cancer, cervix cancer, brain cancer and kidney cancer ${ }^{12}$ (Figs. 5 and 6).

Lung cancer accounts for $17.1 \%$ of cancer deaths in women, and it is followed by breast cancer. The number of deaths from lung cancer in women in 2016 amounted to 7,635 (crude rate: 38.5/100,000), which means a significant increase compared to the oldest available data from the year 1965, when 812 deaths from lung cancer in women in Poland were recorded (5.0). For 40 years an increasing trend for lung cancer deaths in women has been observed. This trend is particularly evident in the group of the oldest women, aged over 65. Mortality rate for lung cancer among women in Poland is lower than in the EU (standardized mortality rates per 100,000 in 2013 were 16.7 and 20.6 respectively). ${ }^{12,17}$

Breast cancer is the second type of cancer that causes the biggest number of deaths in women in Poland. In 2016, the number of deaths from breast cancer amounted to 6,493 (crude rate: $32.7 / 100,000$ ), and in 1965 this number was 1,938 (12.0). Until the 1980s, a significant increase in women's breast cancer mortality was observed in Poland, which was followed by the stabilization period. Since the 1990s, a decrease in women's mortality from breast cancer has been observed. Mortality from breast cancer among women in Poland is about $20 \%$ lower than in the EU countries (standardized mortality rate per 100,000

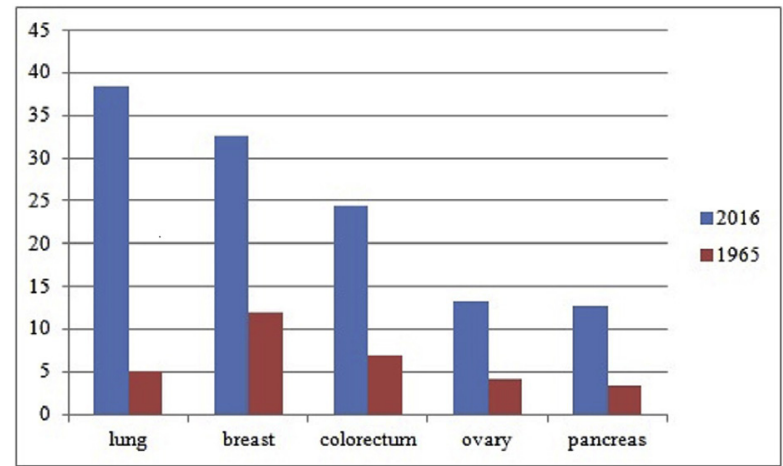

Fig. 6. Cancer mortality among women in 2016 and 1965 (crude rate). for Poland is 14.5 and for the EU countries it is 22.4). ${ }^{15}$

Colorectal cancer is the third cause of cancer deaths among women. ${ }^{27}$ The number of deaths from colorectal cancer in women in Poland in 2016 amounted to 4,936 (crude rate: 24.5/100,000). The number of deaths 50 years earlier (in 1965) was 1,125 (crude rate: 6.9). The increase in colorectal cancer mortality was the biggest before 1995, after which stabilization period came. ${ }^{28}$ The incidence standardized rate (per 100,000) in women with colorectal cancer in Poland is 10.2 and it is lower than in the EU (14.2). ${ }^{19}$

Ovarian cancer is the fourth most common cause of cancer deaths among women in Poland, accounting for over 2.6 thousand deaths (crude rate in 2016: 13.3/100,000). In 1965, the number of deaths from ovarian cancer was significantly lower and amounted to 682 (4.2). The fastest increase in women's mortality from ovarian cancer in all age groups was observed until the 1990s. Mortality rate for ovarian cancer in Poland is about $15 \%$ higher than in the EU. ${ }^{21}$

Pancreatic cancer accounts for approximately $6 \%$ of cancer deaths in women. The number of deaths from pancreatic cancer reported in 2016 in women in Poland amounted to 2,512 (crude rate: 12.7/ 100,000), whereas in 1965 it was 536 (3.3). There was an upward mortality trend until the end of the $1980 \mathrm{~s},{ }^{29}$ after which a period of stabilization started. Deaths from pancreatic cancer occur mainly in women aged over 50 (95\%), and the risk of death increases significantly with age. Pancreatic cancer mortality in Poland remains at a similar level as in the EU, in both cases the standardized rates amount to approx. $5 / 100,000 .^{30}$

\section{Cancer mortality among men}

In 2016, there were 55,253 deaths due to cancer in men in Poland. Until the 1980s, a significant increase in cancer mortality among men was observed, followed by the suppression of this increase. In comparison to EU countries, the standardized male cancer mortality rate per 100,000 in Poland is lower and in 2013 it was 167.4 compared to 211.9 in the EU. ${ }^{11}$

The predominant cause of death due to cancer among men in Poland is lung cancer responsible for every third cancer deaths, followed by colorectal cancer (11.5\% deaths), prostate cancer (9.4\%), stomach cancer $(6.1 \%)$, bladder cancer $(5.4 \%)$ (Table 1$)$. Other cancers that contribute to the highest mortality among men are: pancreatic cancer, kidney cancer, brain tumors, laryngeal cancer and esophageal cancer (Figs. 7 and 8).

Lung cancer accounts for $29.3 \%$ of deaths due to cancer in men. In 2016, the number of deaths from lung cancer among men in Poland amounted to 16,177 (crude rate was 87.0/100,000) and for comparison in 1965 , the number was 3,880 (25.4). The increase in mortality from lung cancer in men was observed until the 1990s, followed by a drop in mortality rates. ${ }^{24}$ The mortality rate for lung cancer among men in Poland is lower than in the EU (standardized mortality rates per 100,000 in 2013 were respectively 51.8 and 56.4). ${ }^{17}$

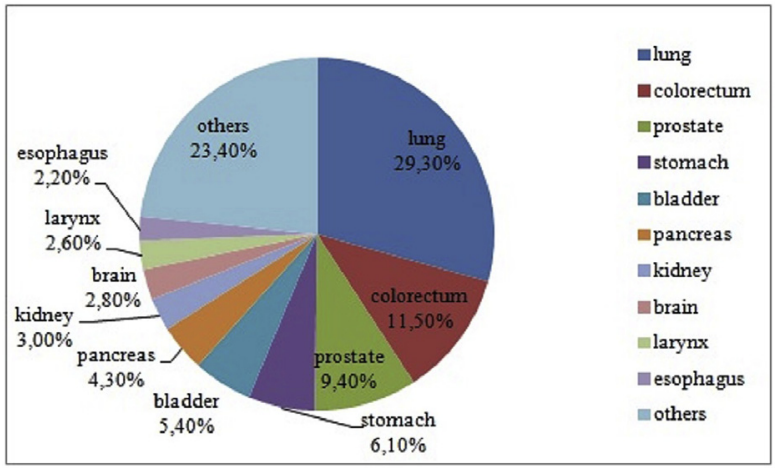

Fig. 7. Cancer mortality among men, 2016. 


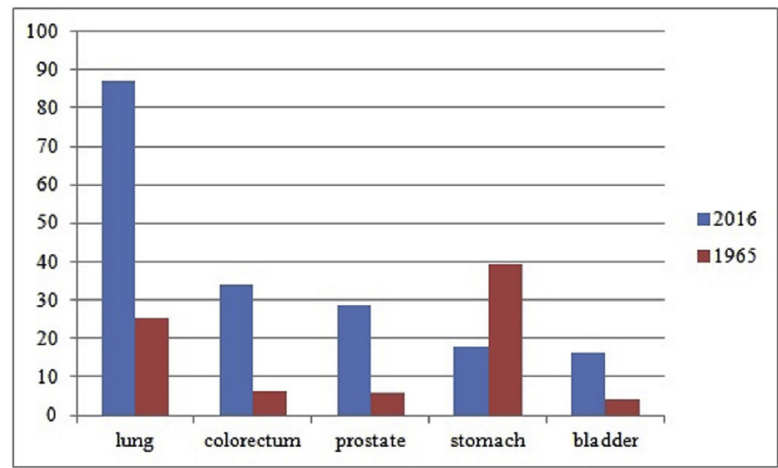

Fig. 8. Cancer mortality among men in 2016 and 1965 (crude rate).

Colorectal cancer is the second most common cause of cancer deaths among men. ${ }^{27}$ In 2016, the number of deaths from colorectal cancer in men in Poland was 6,321 (crude rate: 34.0/100,000), and in 1965 - 961 (6.3). In the last 30 years, a constant increase in mortality has been observed among men. ${ }^{28}$ The mortality rate of colorectal cancer among men in Poland is lower than in EU countries (standardized ratio in 2013 was 19.3/100,00 for Poland and 23.8 for EU). ${ }^{19}$

Prostate cancer is the third most common cause of cancer deaths among men in Poland. In 2016, 5,220 men died in Poland due to prostate cancer (crude rate: $28.8 / 100,000$ ) and in 1965, this number was 895 (5.9). The increase in mortality due to prostate cancer was recorded in Poland until the 21st century, and then it has stabilized. The mortality rate due to prostate cancer in Poland is slightly higher than the average for EU countries (12.4/100,000 for Poland and 12.1/ 100,000 for EU in 2013). ${ }^{23}$

Stomach cancer is the fourth cause of cancer deaths among men in Poland. However, the number of reported deaths is systematically decreasing - in 2016 it amounted to 3,353 (crude rate: 18.0/100,000), and for comparison in 1965, 5,990 (39.2). However, the mortality rate of stomach cancer in Poland is much higher than in the EU countries (among men by $25 \%)^{26}$

In recent years, bladder cancer causes 2.5-3,000 deaths per year among men in Poland (2016-2,967, crude rate 16.0/100,000). In 1965, the number of deaths was 633 (4.1). The largest increase in mortality was observed until the 1990s. The mortality rate due to bladder cancer among men in Poland is about 50\% higher than in EU countries. ${ }^{25}$

\subsection{Factors contributing to trends in cancer occurrence}

The changes observed in recent years in cancer incidence and mortality in Poland are primarily associated with the demographic structure of the population, in which an increasing percentage are people over 65 years of age ( $13 \%$ of men and $19 \%$ of women). ${ }^{12}$ In this age group, cancers are diagnosed most often. Other important factors contributing to these changes (apart from genetic factors) are also health behaviors of the population, including the level of exposure to carcinogens. The health care system and prevention or screening carried out under public measures also play an important role.

\subsection{Lifestyle factors}

Smoking is the main factor affecting changes in the structure of cases and deaths from cancer. ${ }^{1,3,8,29,35,36}$ On the one hand, this is evident in the significant increase in lung cancer incidence and mortality in the female population. Available data indicate that for over 10 years lung cancer has been the cause of the highest number of deaths due to cancer among women (previously the main cause of death was breast cancer). On the other hand, the decrease in the percentage of smoking men in Poland has reduced the incidence and mortality from lung cancer. It should be emphasized that smoking is a significant factor in the development of colorectal cancer, bladder cancer, where it accounts for $50-65 \%$ of cancer cases among men and $20-30 \%$ of cases among women, or pancreatic cancer (20-30\% of cancers caused by smoking). The second important factor affecting cancer is the alcohol consumption, which is responsible for $2-4 \%$ of cancer cases, and analyzing the most common cancers occurring in Poland is particularly important in the development of breast cancer. ${ }^{1,3,12,35,36}$

Obesity and an inadequate diet, which is highly processed, rich in animal fats, salt, preserved and smoked products, and poor in plant products are also of great importance in the incidence of cancer. These factors predispose to the development of breast, endometrial, pancreas, colorectal or stomach cancer, ${ }^{1,3,8,18,28,35,36}$ although in the case of stomach cancer a downward trend in morbidity and mortality is observed, which may be associated with a common change in food storage methods (freezing products instead of salting and smoking), which significantly reduced the incidence of Helicobacter pylori infections. ${ }^{3,36}$

Another important factor affecting the incidence of cancer is low physical activity, associated primarily with colorectal cancer, but also breast or endometrial cancer. ${ }^{1,18,28,35,36}$

\subsection{Factors related to the health care system}

Changes in the number of cases and deaths due to the most common cancer in Poland may result from preventive measures, rapid diagnosis or increasingly effective cancer treatment, including surgery, radiotherapy, hormone therapy or chemotherapy, in most cases financed from public funds. The Cancer Control Strategy for Poland has been operating in Poland since 2006 (current version for 2015-2024), guaranteeing both educational activities and screening towards the most common cancer diseases.

In the case of breast cancer, women aged 50-69 are covered by mammograms, which are performed every 2 years. Preventive tests are also used to detect colorectal cancer (fecal occult blood test performed every year for people over 50 and endoscopic tests for people over 55 years of age). In the field of lung cancer, a separate program has been developed, which includes free computed tomography (CT) for people at specific risk groups, or an early detection program for prostate cancer. In relation to stomach cancer, due to the lack of screening in Poland, it is recommended to perform an endoscopic examination of the upper gastrointestinal tract in case of persistent dyspeptic symptoms. Eradication of Helicobacter pylori using antibiotic therapy is also a preventive measure.

It is also worth noting that the introduction of screening tests may affect the sudden increase in reported cancer cases, ${ }^{1,2}$ since all cases (asymptomatic) are detected, and only in the following years real new cases are recorded. In addition, in Poland, until the mid-1980s, deficiencies in cancer registration completeness are observed. Despite the publication of the number of cases and deaths from cancer since 1979, the detailed structure of the National Cancer Registry was published in 2013. ${ }^{12}$

When discussing the area of the healthcare system, it should be emphasized that one of the most important factors influencing changes in mortality trends is the stage of cancer advancement. ${ }^{8,36}$ A significant change in this area is observed in Poland, which results from both the growing health awareness of the society and the quality of basic health care. In recent years, more and more early detection is being reported, ${ }^{12}$ which may explain the stabilization and decreasing mortality of many types of cancer.

\section{Conclusions}

It is estimated that by the year 2030 aging of the society and unfavorable lifestyle changes (insufficient physical activity, poor diet, stimulants) will result in the increase in new cancer cases up to 21.7 million and in the number of deaths up to 13 million or more. ${ }^{31}$

In addition to being a health problem, cancer has become a social 
and economic burden due to long-term treatment, reduced quality of life, reduced productivity, considerable absenteeism from work, and the necessity of receiving help from relatives. ${ }^{32-34}$ Cancer in Poland affects mainly middle-aged people, especially the population of women aged under 65, who are in the productive age, and among which cancer is the main cause of deaths.

In view of the abovementioned findings, a plan for long-term cancer treatment should become a priority in health policies. An important aspect in this respect is adequate financing of oncological treatment, screening tests for the early detection of cancer and rehabilitation, which should all be based on medical technologies that are clinically efficient, cost-effective, and can bring long-term health benefits. ${ }^{35,36}$

An important element of providing care to cancer patients is comprehensive and long-term psychological care. ${ }^{37}$ Cancer affects the psyche of the ill person, thus becoming a source of stress and negative emotions, which translates into low acceptance of disease and lifestyle modifications. Acceptance of cancer and attempts to cope with the disease significantly affect the patient's perception of their quality of life. Scientific literature shows that there is a close link between patient's approach to cancer and the feeling of pain, or even the chance of survival. ${ }^{38-40}$ Therefore, providing patients with psychological help of clinical psychologists can bring benefits both to patients and healthcare systems.

\section{Declaration of competing interest}

None.

\section{References}

1. Jemal A, Bray F, Center MM, Ferlay J, Ward E, Forman D. Global cancer statistics. CA A Cancer J Clin. 2011;61:69-90.

2. Antoni S, Soerjomataram I, Møller B, Bray F, Ferlay J. An assessment of GLOBOCAN methods for deriving national estimates of cancer incidence. Bull World Health Organ. 2016;94:174-184.

3. Bray F, Ferlay J, Soerjomataram I, Siegel RL, Torre LA, Jemal A. Global cancer statistics 2018: GLOBOCAN estimates of incidence and mortality worldwide for 36 cancers in 185 countries. CA A Cancer J Clin. 2018 Nov;68(6):394-424.

4. International Agency for Research on Cancer. All cancers. . [cited 2019 Jul 20]. Available from: http://gco.iarc.fr/today/data/factsheets/cancers/39-All-cancersfact-sheet.pdf; March 2019.

5. Eurostat. Cancer statistics. . [cited 2019 Jul 23]. Available from:. https://ec.europa. eu/eurostat/statistics-explained/index.php/Cancer_statistics.

6. OECD/EU. Health at a Glance: Europe 2016 - State of Health in the EU Cycle. Paris: OECD Publishing; 20162016.

7. International Agency for Research on Cancer, Europe. . [cited 2019 Jul 23]. Available from:. https://gco.iarc.fr/today/data/factsheets/populations/908-europe-factsheets.pdf; March 2019.

8. Ferlay J, Colombet M, Soerjomataram I, et al. Cancer incidence and mortality patterns in Europe: estimates for 40 countries and 25 major cancers in 2018. Eur J Cancer. 2018 Nov;103:356-387.

9. Smoleń E, Hombek K, Jarema M, Słysz M, Kalita K. Factors determining the acceptance of the disease in patients treated oncologically. Med OgNauk Zdr. 2018;24(1):37-43.

10. International Agency for Research on Cancer. Cancer Screening in the European Union. Report on the implementation of the Council. Recommendation on cancer screening. 2017; 2017 Lyon 2017.

11. National Cancer Registry. Malignant neoplasms in general. . [cited 2019 Jul 12]. Available from:. http://onkologia.org.pl/nowotwory-zlosliwe-ogolem-2/.

12. Wojciechowska U, Czaderny K, Ciuba A, Olasek P, Didkowska J. Malignancies in Poland in 2016. Warsaw: Center of Oncology - Maria Skłodowska-Curie Institute;
2018. [cited 2019 March 10]. Available from:. http://onkologia.org.pl/wp-content/ uploads/Nowotwory 2016.pdf.

13. Wojtyniak B, Stokwiszewski J, Goryński P, Zdrojewski T. Life expectancy and mortality of the Polish population. In: Wojtyniak B, Stokwiszewski J, Goryński P, eds. The Health Situation of the Polish Population. Warsaw: National Institute of Public Health National Institute of Hygiene; 2008:85.

14. Godlewski D, Adamczak M, Wojtyś P. Experiences of cancer patients in Poland throughout diagnosis and treatment. Eur J Cancer Care. 2017;26(2):e12436.

15. National Cancer Registry. Breast cancer in women. . [cited 2019 Jun 22]. Available from:. http://onkologia.org.pl/nowotwory-piersi-kobiet/.

16. Sułkowska U, Mańczuk M, Łobaszewski J, Zatoński WA. Lung cancer, the leading cause of cancer deaths among women in Europe. Nowotw J Oncol. 2015;65(5):395-403.

17. National Cancer Registry. Pleural and lung cancer. . [cited 2019 Jun29]. Available from:. http://onkologia.org.pl/nowotwory-zlosliwe-oplucnej-pluca-c33-34/.

18. Fidler MM, Bray F, Vaccarella S, Soerjomataram I. Assessing global transitions in human development and colorectal cancer incidence. Int J Cancer. 2017 Jun 15;140(12):2709-2715

19. National Cancer Registry. Colorectal cancer. . [cited 2019 Jun 29]. Available from:. http://onkologia.org.pl/nowotwory-zlosliwe-jelita-grubego-c18-21/.

20. National Cancer Registry. Endometrial cancer. . [cited 2019 Jun 29]. Available from:. http://onkologia.org.pl/nowotwory-trzonu-macicy-kobiet-c54/.

21. National Cancer Registry. Ovarian cancer. . [cited 2019 Jun 29]. Available from:. http://onkologia.org.pl/nowotwory-jajnika-c56/.

22. Osowiecka K, Nawrocki S, Kurowicki M, Rucińska M. The waiting time of prostate cancer patients in Poland. Int J Environ Res Public Health. 2019;16(3):342.

23. National Cancer Registry. Prostate cancer. . [cited 2019 March 10]. Available from: http://onkologia.org.pl/nowotwory-zlosliwe-gruczolu-krokowego-c61/.

24. Didkowska J, Wojciechowska U, Mańczuk M, Łobaszewski J. Lung cancer epidemiology: contemporary and future challenges worldwide. Ann Transl Med. 2016 Apr;4(8):150.

25. National Cancer Registry. Bladder cancer. . [cited 2019 Jul 23]. Available from:. http://onkologia.org.pl/nowotwory-zlosliwe-pecherza-moczowego-c67/.

26. National Cancer Registry. Gastric cancer. . [cited 2019 Jul 14]. Available from: http://onkologia.org.pl/nowotwory-zlosliwe-zoladka-c16/.

27. Dahms S, Nowicki A. Epidemiology and results of treatment of colorectal cancer in Poland. Pol Przegl Chir. 2015;87(11):598-605.

28. Malvezzi M, Carioli G, Bertuccio P, et al. European cancer mortality predictions for the year 2018 with focus on colorectal cancer. Ann Oncol. 2018 Apr 1;29(4):1016-1022.

29. Ilic M, Ilic I. Epidemiology of pancreatic cancer. World J Gastroenterol. 2016 Nov 28;22(44):9694-9705.

30. National Cancer Registry. Pancreatic cancer. . [cited 2018 Dec 12]. Available from:. http://onkologia.org.pl/nowotwory-trzustki-c25-c26/.

31. Bray F, Jemal A, Grey N, Ferlay J, Forman D. Global cancer transitions according to the Human Development Index (2008-2030): a population-based study. Lancet Oncol. 2012;13:790-801.

32. Ekwueme DU, Trogdon JG, Khavjou OA, Guy Jr GP. Productivity costs associated with breast cancer among survivors aged 18-44 years. Am J Prev Med. 2016 Feb;50(2):286-294.

33. Hanly P, Soerjomataram I, Sharp L. Measuring the societal burden of cancer: the cost of lost productivity due to premature cancer-related mortality in Europe. Int $J$ Cancer. 2015 Feb 15;136(4):E136-E145.

34. Yin W, Horblyuk R, Perkins JJ, et al. Association between breast cancer disease progression and workplace productivity in the United States. $J$ Occup Environ Med. 2017 Feb;59(2):198-204

35. Torre LA, Siegel RL, Ward EM, Jemal A. Global cancer incidence and mortality rates and trends-an update. Cancer Epidemiol Biomark Prev. 2016 Jan;25(1):16-27.

36. Arem H, Loftfield E. Cancer epidemiology: a survey of modifiable risk factors for prevention and survivorship. Am J Lifestyle Med. 2018 May-Jun;12(3):200-210.

37. Dieng M, Cust AE, Kasparian NA, Mann GJ, Morton RL. Economic evaluations of psychosocial interventions in cancer: a systematic review. Psycho Oncol. 2016 Dec;25(12):1380-1392.

38. Secinti E, Tometich DB, Johns SA, Mosher CE. The relationship between acceptance of cancer and distress: a meta-analytic review. Clin Psychol Rev. 2019 Jul;71:27-38.

39. Nipp RD, Greer JA, El-Jawahri A, et al. Coping and prognostic awareness in patients with advanced cancer. J Clin Oncol. 2017 Aug 1;35(22):2551-2557.

40. Tojal C, Costa R. Depressive symptoms and mental adjustment in women with breast cancer. Psycho Oncol. 2015;24(9):1060-1065. 